\title{
Epigenome-wide association study of DNA methylation in panic disorder
}

Mihoko Shimada-Sugimoto', Takeshi Otowa ${ }^{2^{*}}$, Taku Miyagawa ${ }^{1,3}$, Tadashi Umekage ${ }^{4}$, Yoshiya Kawamura ${ }^{5}$, Miki Bundo ${ }^{6}$, Kazuya Iwamoto ${ }^{6}$, Mamoru Tochigi ${ }^{7}$, Kiyoto Kasai ${ }^{8}$, Hisanobu Kaiya ${ }^{9}$, Hisashi Tanii ${ }^{10}$, Yuji Okazaki ${ }^{11}$, Katsushi Tokunaga ${ }^{1}$ and Tsukasa Sasaki ${ }^{12}$

\begin{abstract}
Background: Panic disorder (PD) is considered to be a multifactorial disorder emerging from interactions among multiple genetic and environmental factors. To date, although genetic studies reported several susceptibility genes with PD, few of them were replicated and the pathogenesis of PD remains to be clarified. Epigenetics is considered to play an important role in etiology of complex traits and diseases, and DNA methylation is one of the major forms of epigenetic modifications. In this study, we performed an epigenome-wide association study of PD using DNA methylation arrays so as to investigate the possibility that different levels of DNA methylation might be associated with PD.
\end{abstract}

Methods: The DNA methylation levels of $\mathrm{CpG}$ sites across the genome were examined with genomic DNA samples ( $\mathrm{PD}, N=48$, control, $N=48$ ) extracted from peripheral blood. Methylation arrays were used for the analysis. $\beta$ values, which represent the levels of DNA methylation, were normalized via an appropriate pipeline. Then, $\beta$ values were converted to $M$ values via the logit transformation for epigenome-wide association study. The relationship between each DNA methylation site and PD was assessed by linear regression analysis with adjustments for the effects of leukocyte subsets.

Results: Forty CpG sites showed significant association with PD at 5\% FDR correction, though the differences of the DNA methylation levels were relatively small. Most of the significant CpG sites (37/40 CpG sites) were located in or around CpG islands. Many of the significant CpG sites (27/40 CpG sites) were located upstream of genes, and all such CpG sites with the exception of two were hypomethylated in PD subjects. A pathway analysis on the genes annotated to the significant CpG sites identified several pathways, including "positive regulation of lymphocyte activation."

Conclusions: Although future studies with larger number of samples are necessary to confirm the small DNA methylation abnormalities associated with PD, there is a possibility that several $\mathrm{CpG}$ sites might be associated, together as a group, with PD.

Keywords: DNA methylation, Panic disorder, Epigenome-wide association study, Epigenetics, Psychiatric disorder

\footnotetext{
* Correspondence: totowa-psy@umin.org

${ }^{2}$ Graduate School of Clinical Psychology, Teikyo Heisei University Major of

Professional Clinical Psychology, 2-51-4 Higashiikebukuro, Toshima Ward,

Tokyo 171-0014, Japan

Full list of author information is available at the end of the article
} 


\section{Background}

Panic disorder (PD) is a major anxiety disorder characterized by recurrent unexpected panic attacks and anticipatory anxiety. According to previous twin and family studies [1-3], PD is considered to be a multifactorial disorder emerging from the interactions between multiple genetic and environmental factors. Recently, genomewide association studies (GWASs), whole-exome sequencing and meta- analyses were performed [4-8] and identified transmembrane protein 132D (TMEM132D) and catechol-O-methyltransferase (COMT) as PD susceptibility genes $[4,5]$. However, there would be other genetic factors associated with PD.

Epigenetics is one of the biological fields that is considered to play an important role in the etiology of complex diseases [9]. The term "epigenetics" is now generally understood to refer to potentially heritable and functionally relevant to gene expression and chromatin structure with no changes to genetic sequences [9, 10]. DNA methylation is one of the major forms of epigenetic modifications that was found to play important roles in the context of gene regulation [11]. Moreover, a part of the DNA methylation is reported to be involved in the pathogenesis of psychiatric disorders, including anxiety disorders $[12,13]$.

Previous studies on DNA methylation in anxiety disorders have focused mainly on candidate genes that were reported to be involved in the stress response, neurotransmission, and neuroplasticity [14]. One recent study conducted in social anxiety disorder (SAD) patients reported an association between SAD and oxytocin receptor $(O X T R)$ gene hypomethylation [15]. Hypomethylation of the promoter and intron 2 region in another candidate gene, glutamate-decarboxylase 1 (GAD1), was also reported in PD patients [16]. Another preliminary study showed that $\mathrm{CpG}$ sites in monoamine oxidase A $(M A O A)$ were significantly less methylated in PD patients than in healthy controls $[17,18]$ and negative life events were associated with this lower level of DNA methylation [18]. In another study, solute carrier family 6, member 4 (SLC6A4) and serotonin transporter $(S E R T)$ were examined in children with anxiety disorders before and after cognitive behavior therapy; a DNA methylation change in SLC6A4 was related to response to the psychological therapy, as responders had increased SLC6A4 methylation [19]. Methylation of another neurotransmitter transporter, noradrenaline transporter $(N E T)$, also known as solute carrier family 6, member 2 (SLC6A2), was also studied in subjects with $\mathrm{PD}$ and hypertension; results showed that DNA hypermethylation in the promoter region of $N E T$ caused NET gene silencing through the binding of methyl-CpG binding protein 2 (MeCP2), a methylation-related inhibitory transcription factor $[20,21]$. However, results from another study did not support the finding of significant changes in SLC6A2 promoter methylation in the patients with PD or major depressive disorder [22]. Overall, the results from such previous studies suggest the importance of DNA methylation abnormalities in the pathogenesis of PD, although the number of studies and the sample sizes have been limited and most of the findings have not been confirmed in replication studies.

Recently, a genome-wide approach has enabled the examination of DNA methylation patterns without any prior information. A methylation array (Infinium ${ }^{\bullet}$ Human Methylation $450 \mathrm{~K}$ BeadChip, Illumina Inc., San Diego, CA, USA) can simultaneously detect the DNA methylation status of more than 480,000 cytosine residues across the genome. This array has been used to successfully identify DNA methylation marks related to aging [23, 24], leukocyte subsets [25], smoking [26], and disease outcomes $[27,28]$. As far as we know, there has been no report of the examination of genome-wide DNA methylation patterns in PD.

In this study, we performed an epigenome-wide association study (EWAS) of PD using the array technology. DNA samples extracted from peripheral blood were utilized. Although an EWAS using brain tissue would be more appropriate for identifying disease-associated differentially methylated positions (DMPs), peripheral blood is more accessible and might enable the development of diagnostic biomarkers. Here, we examined the genome-wide DNA methylation profiles of 48 PD subjects and 48 age- and sex-matched control subjects to investigate aberrant differences in DNA methylation that are related to PD.

\section{Results}

\section{Quality check of the DNA methylation array data}

In the DNA methylation array analysis, each probe signal for a sample had a detection $P$ value calculated as the probability that a target signal is distinguishable from the negative controls to show the overall probe performance. We confirmed that more than $99 \%$ of all probes in all samples had a detection $P$ value $\leq 0.05$, showing that the overall performance of the assay was high. Principal component analysis using probes on the $\mathrm{X}$ chromosome was performed to predict the gender of samples in this study. The result showed that all samples were correctly labeled in the gender groups (Additional file 1: Figure S1). Density plots of the $\beta$ values were prepared from the raw data of each sample for a visual inspection. All plots showed a standard bimodal distribution of the $\beta$ values (Additional file 1: Figure S2) with the same characteristics of the distribution described in a previous study [29]. The distribution of DNA methylation was bimodal with a minority of probes showing intermediate DNA methylation levels. The DNAm age 
was estimated using the results of approximately 350 probes, and the Pearson's correlation coefficients between the estimated DNAm age and chronological age were calculated to be 0.77 and 0.90 in PD and control groups, respectively, which is considered to support the data quality of this method (Additional file 1: Figure S3).

\section{Prediction of the distribution of leukocyte subsets}

The proportions of leukocyte subsets (natural killer cells, $\mathrm{B}$ cells, $\mathrm{CD} 4^{+} \mathrm{T}$ cells, $\mathrm{CD}^{+} \mathrm{T}$ cells, monocytes, and granulocytes) were estimated from the DNA methylation array data using a published algorithm [30]. Wilcoxon's rank-sum tests using the estimated proportion of each leukocyte subset were performed to examine whether the compositions of leukocyte cells differed between the $\mathrm{PD}$ and control subjects. The proportion of $\mathrm{CD} 4^{+} \mathrm{T}$ cells was significantly higher in the PD subjects than in the control subjects $(P=0.0034)$ (Fig. 1$)$. To further interpret the result of the prediction of leukocyte subsets, the abundance measures of plasmablasts, $\mathrm{CD} 8^{+} \mathrm{CD} 28^{-}$ $\mathrm{CD}_{45 \mathrm{RA}^{-}} \mathrm{T}$ cells, naive $\mathrm{CD} 8^{+} \mathrm{T}$ cells, and naive $\mathrm{CD} 4^{+} \mathrm{T}$ cells were estimated and compared between $\mathrm{PD}$ and control subjects, resulting that no significant difference was observed (Additional file 1: Figure S4).

\section{EWAS of PD and control subjects}

With the DNA methylation array experiment, the methylation status of a total of 485,512 cytosine residues were examined. We filtered out the low quality probes and those on sex chromosomes, and finally, 376,602 probes remained (Additional file 1: Figure S5). The data were normalized via the pipeline, Lumi: $\mathrm{QN}+\mathrm{BMIQ}+\mathrm{ComBat}$. We then performed an EWAS of PD. The Q-Q plot was showed in Additional file 1: Figure S6. After excluding three possible crossreactive probes, 40 probes showed significant association with PD when the false discovery rate (FDR) was set to $5 \%$ (Table 1, Fig. 2). The most significant probe, cg25270498, was located upstream of the meteorin, glial cell differentiation regulator-like (METRNL) gene and was significantly hypomethylated in PD patients (FDR $q$ value $\left.=1.19 \times 10^{-4}\right)$, followed by $\operatorname{cg} 05910615$ (HSPB6; C19orf55, FDR $q$ value $=1.19 \times 10^{-4}$ ) and $\operatorname{cg} 20340149$ $\left(C L A S P 1\right.$, FDR $q$ value $\left.=8.64 \times 10^{-4}\right)$. At many of the CpG sites with significantly different levels of DNA methylation, the cytosine residues were less methylated in the PD subjects than in the control subjects (Fig. 2). Only eight CpG sites were found to be significantly more methylated in the PD subjects than in the control subjects. Most of the significant CpG sites (37/40 CpG sites) were located in $\mathrm{CpG}$ island or $\mathrm{CpG}$ island shore and shelf that span up to $2 \mathrm{~kb}$ and $2-4 \mathrm{~kb}$ from $\mathrm{CpG}$ islands, respectively (Table 1). Many of them (27/40 CpG sites) were located upstream (within 1500 bp from the transcriptional start site, the $5^{\prime}$ untranslated region and the first exon) of genes, and these $27 \mathrm{CpG}$ sites other than two were all hypomethylated in PD subjects (Table 1).

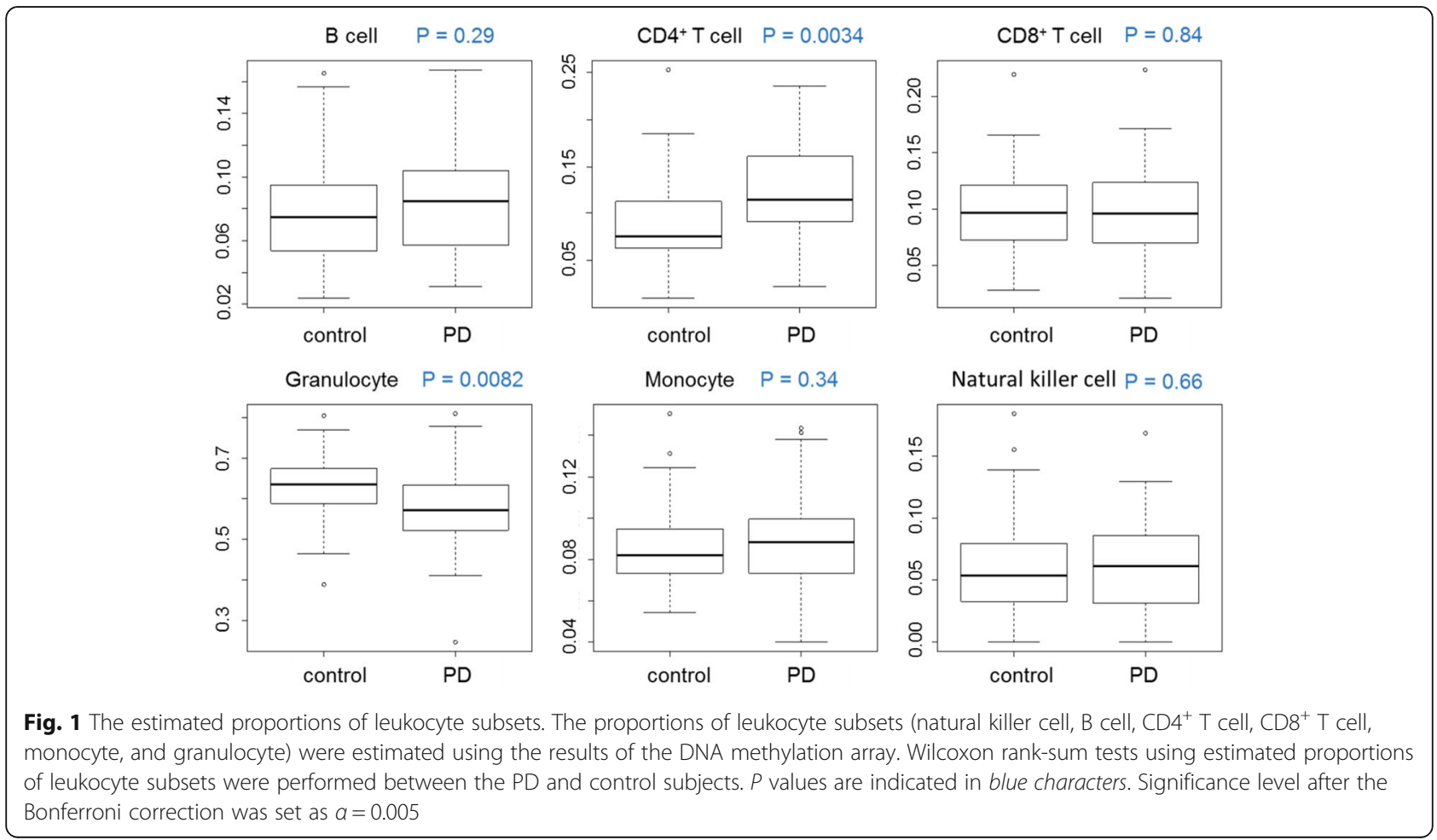


Table 1 Probes with significant differential DNA methylation status between PD and control

\begin{tabular}{|c|c|c|c|c|c|c|c|c|c|c|c|}
\hline \multirow[t]{2}{*}{$\mathrm{CHR}$} & \multirow[t]{2}{*}{$\begin{array}{l}\text { Position } \\
\text { (hg19) }\end{array}$} & \multirow[t]{2}{*}{ Target ID } & \multicolumn{2}{|c|}{$\begin{array}{l}\text { Mean } \\
\beta \text { value }\end{array}$} & \multicolumn{2}{|c|}{$\begin{array}{l}\text { Mean Adjusted } \\
\text { M value }\end{array}$} & \multirow[b]{2}{*}{$P$ value } & \multirow[b]{2}{*}{ q value } & \multirow[t]{2}{*}{ Genes } & \multirow[t]{2}{*}{$\begin{array}{l}\text { Location with respect } \\
\text { to genes }\end{array}$} & \multirow{2}{*}{$\begin{array}{l}\text { Relation } \\
\text { to CpG } \\
\text { Islad }^{\mathrm{a}}\end{array}$} \\
\hline & & & $\overline{\mathrm{PD}}$ & Control & $\overline{\mathrm{PD}}$ & Control & & & & & \\
\hline 17 & 81037414 & cg25270498 & 0.257 & 0.283 & -1.71 & -1.53 & $5.67 \times 10^{-10}$ & $1.19 \times 10^{-4}$ & METRNL & TSS200 & Island \\
\hline 19 & 36248877 & cg05910615 & 0.222 & 0.251 & -2.05 & -1.81 & $6.30 \times 10^{-10}$ & $1.19 \times 10^{-4}$ & HSPB6;C19orf55 & TSS1500;TSS200 & N_Shore \\
\hline 2 & 122407145 & cg20340149 & 0.152 & 0.175 & -2.73 & -2.49 & $6.88 \times 10^{-9}$ & $8.64 \times 10^{-4}$ & CLASP1 & TSS200 & Island \\
\hline 13 & 80055594 & cg14777817 & 0.134 & 0.153 & -2.90 & -2.69 & $5.17 \times 10^{-8}$ & $4.87 \times 10^{-3}$ & NDFIP2 & 1stExon & Island \\
\hline 10 & 135088451 & cg25526061 & 0.147 & 0.164 & -2.79 & -2.56 & $1.30 \times 10^{-7}$ & $7.64 \times 10^{-3}$ & ADAM8 & Body & N_Shore \\
\hline 17 & 27224823 & cg04266864 & 0.133 & 0.151 & -2.97 & -2.73 & $1.42 \times 10^{-7}$ & $7.64 \times 10^{-3}$ & FLOT2;DHRS13 & TSS200;3'UTR & Island \\
\hline 16 & 12142335 & cg10475689 & 0.606 & 0.576 & 0.82 & 0.63 & $2.09 \times 10^{-7}$ & $9.38 \times 10^{-3}$ & RUNDC2A & Body & \\
\hline 16 & 23568708 & cg05742564 & 0.192 & 0.215 & -2.30 & -2.08 & $2.48 \times 10^{-7}$ & $9.38 \times 10^{-3}$ & UBFD1;EARS2 & TSS200;TSS200 & Island \\
\hline 1 & 228604037 & cg02931001 & 0.263 & 0.280 & -1.62 & -1.49 & $2.49 \times 10^{-7}$ & $9.38 \times 10^{-3}$ & TRIM17 & 5'UTR & Island \\
\hline 13 & 28024472 & cg08209163 & 0.147 & 0.165 & -2.73 & -2.54 & $3.45 \times 10^{-7}$ & 0.0118 & MTIF3 & TSS200;5'UTR & Island \\
\hline 12 & 50017361 & cg10727759 & 0.147 & 0.165 & -2.74 & -2.54 & $4.51 \times 10^{-7}$ & 0.0139 & PRPF $40 B$ & TSS200 & Island \\
\hline 22 & 24236284 & cg12738349 & 0.290 & 0.304 & -1.40 & -1.30 & $4.80 \times 10^{-7}$ & 0.0139 & MIF & TSS1500 & Island \\
\hline 3 & 197409980 & cg08942682 & 0.830 & 0.848 & 2.06 & 2.28 & $6.05 \times 10^{-7}$ & 0.0163 & KIAA0226 & Body & \\
\hline 6 & 170597377 & cg05228964 & 0.602 & 0.580 & 0.71 & 0.59 & $7.23 \times 10^{-7}$ & 0.0172 & DLL1 & Body & Island \\
\hline 12 & 4381997 & cg08553284 & 0.316 & 0.330 & -1.20 & -1.11 & $7.57 \times 10^{-7}$ & 0.0172 & CCND2 & TSS1500 & Island \\
\hline 1 & 155164676 & cg03425468 & 0.215 & 0.240 & -2.10 & -1.88 & $7.78 \times 10^{-7}$ & 0.0172 & MIR92B & TSS1500 & Island \\
\hline 22 & 38202626 & $\operatorname{cg} 11029475$ & 0.202 & 0.219 & -2.23 & -2.02 & $8.43 \times 10^{-7}$ & 0.0176 & GCAT;H1FO;H1FO & TSS1500;1 stExon;3'UTR & N_Shore \\
\hline 16 & 2732724 & cg02205746 & 0.295 & 0.311 & -1.36 & -1.26 & $9.40 \times 10^{-7}$ & 0.0182 & KCTD5 & 1stExon & Island \\
\hline 17 & 44270511 & $\operatorname{cg} 10256219$ & 0.116 & 0.103 & -2.71 & -2.93 & $9.64 \times 10^{-7}$ & 0.0182 & & & Island \\
\hline 3 & 50375496 & cg09386807 & 0.236 & 0.256 & -1.86 & -1.70 & $1.14 \times 10^{-6}$ & 0.0204 & RASSF1 & TSS1500;Body;5'UTR & Island \\
\hline 8 & 28243934 & cg13411962 & 0.168 & 0.181 & -2.46 & -2.31 & $1.25 \times 10^{-6}$ & 0.0211 & ZNF395 & 5'UTR;1stExon & Island \\
\hline 4 & 4861398 & cg01959412 & 0.325 & 0.339 & -1.17 & -1.07 & $1.29 \times 10^{-6}$ & 0.0211 & MSX1 & 5'UTR;1stExon & Island \\
\hline 11 & 61197477 & cg03342113 & 0.264 & 0.278 & -1.58 & -1.48 & $1.53 \times 10^{-6}$ & 0.0230 & CPSF7;SDHAF2 & TSS200;TSS200 & Island \\
\hline 17 & 42293627 & cg24247482 & 0.556 & 0.557 & 0.50 & 0.39 & $1.53 \times 10^{-6}$ & 0.0230 & UBTF & Body & N_Shelf \\
\hline 17 & 80189962 & $\operatorname{cg} 17932802$ & 0.358 & 0.366 & -0.92 & -0.85 & $1.65 \times 10^{-6}$ & 0.0239 & SLC16A3 & TSS200;5'UTR & Island \\
\hline 1 & 204159498 & cg13065121 & 0.233 & 0.250 & -1.89 & -1.73 & $1.84 \times 10^{-6}$ & 0.0253 & KISSI & 3'UTR & N_Shore \\
\hline 6 & 32055370 & cg26997880 & 0.225 & 0.247 & -1.98 & -1.79 & $1.95 \times 10^{-6}$ & 0.0253 & $T N X B$ & Body & Island \\
\hline 12 & 121148158 & cg19464320 & 0.123 & 0.107 & -2.58 & -2.83 & $2.26 \times 10^{-6}$ & 0.0284 & UNC119B & 1stExon;5'UTR & N_Shore \\
\hline 9 & 87284706 & cg13965062 & 0.230 & 0.243 & -1.85 & -1.75 & $2.39 \times 10^{-6}$ & 0.0290 & NTRK2 & 5'UTR;1 stExon & Island \\
\hline 1 & 245316477 & cg07124903 & 0.102 & 0.088 & -2.88 & -3.14 & $2.47 \times 10^{-6}$ & 0.0290 & & & N_Shore \\
\hline 19 & 11074303 & cg08315613 & 0.574 & 0.570 & 0.59 & 0.48 & $2.54 \times 10^{-6}$ & 0.0290 & SMARCA4 & 5'UTR & S_Shore \\
\hline 2 & 242254519 & cg13009927 & 0.196 & 0.214 & -2.22 & -2.05 & $3.28 \times 10^{-6}$ & 0.0353 & SEPT2;HDLBP & TSS1500;5'UTR & Island \\
\hline 2 & 217559020 & cg03222971 & 0.233 & 0.251 & -1.90 & -1.73 & $3.42 \times 10^{-6}$ & 0.0357 & IGFBP5 & Body & N_Shore \\
\hline 1 & 206223719 & cg26795730 & 0.196 & 0.215 & -2.23 & -2.05 & $3.53 \times 10^{-6}$ & 0.0357 & AVPR1B & TSS1500 & Island \\
\hline 2 & 73144353 & cg15921587 & 0.302 & 0.318 & -1.33 & -1.21 & $3.69 \times 10^{-6}$ & 0.0357 & EMX1 & TSS1500 & Island \\
\hline 13 & 25621328 & $\operatorname{cg} 18098400$ & 0.132 & 0.150 & -2.96 & -2.74 & $3.83 \times 10^{-6}$ & 0.0357 & & & Island \\
\hline 15 & 66993412 & cg25048202 & 0.290 & 0.306 & -1.41 & -1.30 & $3.84 \times 10^{-6}$ & 0.0357 & SMAD6 & TSS1500 & N_Shore \\
\hline 2 & 27718181 & cg04015759 & 0.250 & 0.267 & -1.71 & -1.58 & $3.89 \times 10^{-6}$ & 0.0357 & FNDC4 & TSS200 & Island \\
\hline 15 & 101690195 & cg24378951 & 0.753 & 0.728 & 1.80 & 1.61 & $4.53 \times 10^{-6}$ & 0.0406 & & & \\
\hline 2 & 44059266 & cg15889012 & 0.194 & 0.213 & -2.25 & -2.07 & $4.74 \times 10^{-6}$ & 0.0415 & $A B C G 5$ & Body & S_Shore \\
\hline
\end{tabular}

Abbreviation: CHR chromosome

TSS, transcription start site

UTR, untranslated region

a Each category of "Relation to CpG island" column defines the following regions: Island, CpG island; N_Shore, 0-2 kb upstream of CpG island; S_Shore, 0-2 kb downstream of CpG island; N_Shelf, 2-4 kb upstream of CpG island 


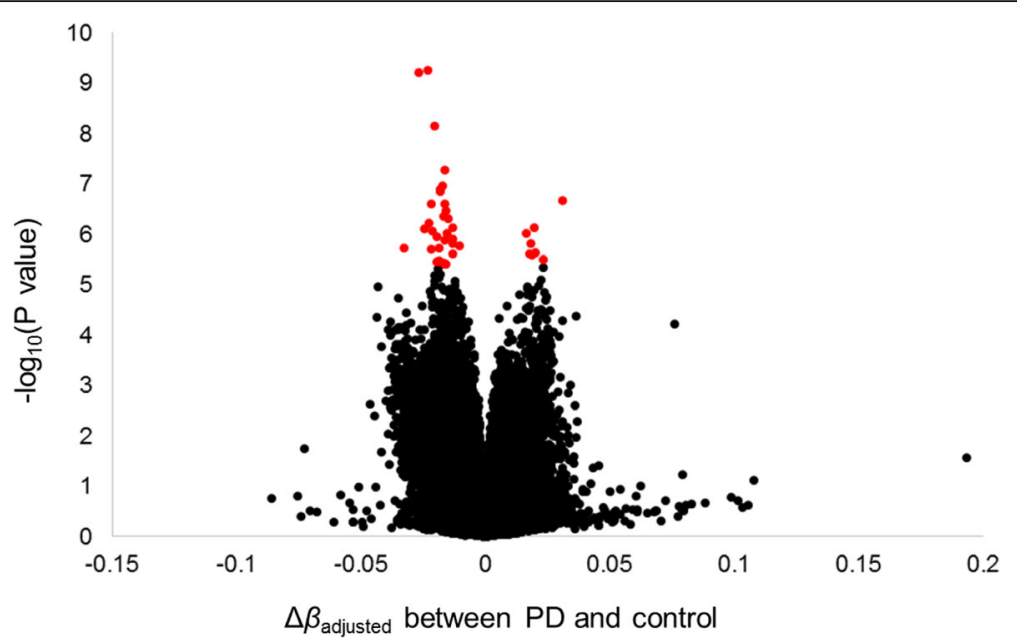

Fig. 2 Results of the EWAS comparing between the PD and control subjects. Log-transformed $P$ values of all the probes were plotted. The

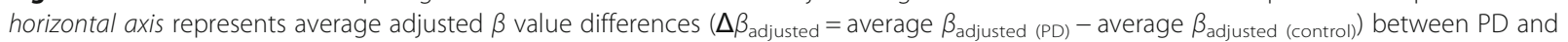
control subjects. Significant probes at 5\% FDR correction are shown in red dots

For confirmation, we examined the possibility that the significant associations were influenced by smoking status. We checked the distributions of adjusted $M$ values of the significant $\mathrm{CpG}$ sites between smokers and nonsmokers among the PD subjects and found that there was no effect of smoking for these sites in PD subjects (Additional file 1: Figure S6).

\section{Pathway analysis}

To assess the overall influence of the significant differences in DNA methylation between the PD and control subjects, a pathway analysis was performed. Annotation information on the 40 significantly associated $\mathrm{CpG}$ sites (Table 1) was used for the analysis; in total, 42 genes were annotated to the $\mathrm{CpG}$ sites. Three gene sets showed significant associations at a FDR of 5\% (Table 2) after we excluded pathways that showed no association in the GOseq pathway analysis in which gene length was taken into consideration. The identified pathways included the "positive regulation of lymphocyte activation" gene set.

\section{Discussion}

In this study, we performed an EWAS of PD using a DNA methylation array and examined the genome-wide
DNA methylation profiles of PD for the first time, as far as we know, although replication is necessary in future studies. This array technology can target $99 \%$ of genes and $95 \%$ of CpG island regions [31] and enables us the analysis of DNA methylation status in a genome-wide manner [32]. Recently, a number of studies have employed this platform to identify differentially DNA methylation sites according to phenotypes. In particular, in the cancer field, this platform has been used to identify a number of DMPs accompanying large $\beta$ value differences in cancer cells $(\geq 0.2)$ [28]. DNA methylation is considered to change according to environmental factors [33, 34]; as such, in psychiatric disorders, it was predicted that the DNA methylation levels at specific sites would differ between patients and healthy subjects [12]. However, in the present study, no DMP showed a large $\beta$ value difference $(\geq 0.2)$ between the PD and control subjects.

In the psychiatric field, epigenetics has been considered to play a role in disease pathogenesis and several recent studies have examined the relationships between DNA methylation and psychiatric disorders in a genomewide manner. For example, an EWAS of major depressive disorder identified more than $350 \mathrm{CpG}$ sites that were associated with the disease and all of these CpG sites were hypomethylated in the major depressive disorder patients8

Table 2 Result of the pathway analysis

\begin{tabular}{llllll}
\hline Gene sets & $\begin{array}{l}\text { Number of genes } \\
\text { in pathways }\end{array}$ & $P$ value & FDR & $\begin{array}{l}\text { Number of genes } \\
\text { in the data }\end{array}$ & Associated genes in the data \\
\hline Epidermis development & 426 & $1.5 \times 10^{-4}$ & 0.017 & 5 & DLL1, FLOT2, IGFBP5, MIF, SMARCA4 \\
Positive regulation of cell cycle & 493 & $3.3 \times 10^{-4}$ & 0.019 & 5 & CCND2, AVPR1B, MIF, RASSF1, MSX1 \\
Positive regulation of lymphocyte activation & 469 & $1.9 \times 10^{-3}$ & 0.037 & 5 & MIF, ADAM8, IGFBP5, AVPR1B, FLOT2 \\
\hline
\end{tabular}


[35] Other EWASs of suicidal behavior or early life stressassociated depression found that the DNA methylation status differed globally between the patients and control subjects [36-38]. In addition, EWASs of schizophrenia identified numerous DMPs associated with the disease; a part of these DMPs were annotated in gene regions previously reported as candidate genes of schizophrenia or psychiatric diseases [39-42]. The results of these previous studies suggest the possibility that in psychiatric disorders, multiple DMPs with small effects $(\beta$ value difference $\leq 0.1$ ) might be associated with diseases together. This would be one explanation for an inflation of $P$ values of the regression analysis observed in this study (Additional file 1: Figure S6), although it cannot be denied that several factors other than age, sex and proportions of leukocyte subsets potentially confounded the result.

In this study, $40 \mathrm{CpG}$ sites were found to be significantly associated with PD. Among these, $27 \mathrm{CpG}$ sites were located upstream of genes and with the exception of two CpG sites, they were all hypomethylated in PD subjects when compared with control subjects. According to previous studies, DNA hypomethylation of upstream gene regions is often associated with a higher level of gene expression [11, 43, 44]. Therefore, such DNA methylation differences upstream of genes may be related to a higher expression level of the annotated genes. We further performed pathway analyses to evaluate the overall influence of the DNA methylation differences. Among the detected gene sets, "positive regulation of lymphocyte activation," which reflected the significant probes annotated to MIF or ADAM8, IGFBP5, AVPR1B, and FLOT2, was particularly intriguing. We previously reported the associations of the immune pathways and the specific $H L A$ allele, $H L A-$ $D R B 1 * 13: 02$, with PD [45]. Furthermore, the most significant probe, cg25270498, located upstream of METRNL, which was reported to possibly act as a cytokine and to exert effects on immune process [46].

In the current study, we also examined the DNA methylation around candidate genes of which DNA methylation statuses were previously reported to be associated with anxiety disorders. The gene regions of $O X T R$, GAD1, SLC6A4, SLC6A2, and MAOA were individually examined. As a result, with our sample set, no significant differences between PD and healthy subjects were observed in these candidate gene regions (Additional file 2: Tables S1-S5). None of the genes annotated to the significant $\mathrm{CpG}$ sites in this study have been identified in previous studies of PD, including GWASs [8, 47]. This might have been partly due to the relatively small sizes of the samples analyzed, or because the CpGs examined using the array were not sufficient in density. Therefore, future detailed studies with larger samples are necessary to further investigate the relationship between the PD candidate genes and DNA methylation.
The proportions of leukocyte subset estimated with the DNA methylation array data were compared between the PD and healthy subjects in this study. As a result, a higher proportion of $\mathrm{CD} 4^{+} \mathrm{T}$ cells $(P=0.0034)$ was found in the PD subjects. A higher tendency of the abundance measure of naive $\mathrm{CD}_{4}^{+} \mathrm{T}$ cell was also observed in PD subjects. As major histocompatibility complex class II molecules, including HLA-DR, interact mainly with $\mathrm{CD} 4^{+} \mathrm{T}$ cells, an increase in $\mathrm{CD} 4^{+} \mathrm{T}$ cells might be a part of an immune abnormality in $\mathrm{PD}$ patients. However, results of previous studies on surface immune phenotypes of lymphocytes did not report consistent results on the up- and down-regulation of leukocyte subsets [48-51]. Additionally, lymphocytes can be affected by environmental factors and/or infection status. Further, the comparisons for leukocyte subsets in this study were not based on cell count or abundance and they were not independent; therefore, further analysis of surface markers by flow cytometry with larger samples is needed to validate the association of $\mathrm{CD} 4^{+} \mathrm{T}$ cells with PD.

There are several limitations to this study: lack of validation and replication studies, use of blood, potential confounding of other factors, and small sample size. First, the current study lacks replication analysis using other DNA methylation measurement such as pyrosequencing. Although replication with pyrosequencing makes the results more reliable, almost all the significant $\mathrm{CpG}$ sites in this study are located in or around $\mathrm{CpG}$ islands. Consequently, it is difficult to design the primers for pyrosequencing. Second, we used DNA extracted from peripheral blood rather than brain samples. Several studies have reported that disease-associated DNA methylation abnormalities can be detected across tissues [39, 42, 52, 53], but there are clear tissue-specific differences in DNA methylation profiles [54, 55]. We checked the blood-brain correlations of the significant $\mathrm{CpG}$ sites of this study, using Blood Brain DNA Methylation Comparison Tool [55]. We found that nine out of 40 significant CpG sites showed the blood-brain correlation $>0.3$, in at least one region of the four examined brain regions (Additional file 3: Table S6). However, we consider that there is a possibility that biological processes in blood such as immune abnormalities are associated with PD [45]. A previous study of multiple sclerosis, an autoimmune disease of the central nervous system, has reported an association of DNA methylation status of a CpG site in blood with the disease [56], supporting our hypothesis. Nevertheless, detailed studies using brain samples are needed to find additional and/or tissue-specific DNA methylation differences associated with PD. Moreover, DNA methylation was found to be influenced by SNP genotypes $[55,56]$. 
The DNA methylation status of a CpG site in multiple sclerosis, which we have mentioned above, is also affected by SNP genotypes [56]. As for the 40 significant probes, two probes, cg07124903 and cg20340149, have previously been reported to be methylation QTLs (meQTLs) in developing brain and are influenced by genetic variations (Additional file 3: Table S7) [57]. We also checked meQTLs identified with blood samples and found that only one probe cg07124903 was reported to be meQTLs (Additional file 3: Table S7) [58]. Additional studies combining the GWAS SNP data and EWAS data might provide new knowledge on the relationships among DNA methylation, SNPs, and PD. Finally, we were unable to take into account the effects of medication for PD and smoking. A previous study reported that long-term medication for schizophrenia decreased DNA methylation of the GAD1 promoter, which was hypermethylated in a mouse model of schizophrenia [59]. Most of the PD patients in the present study were prescribed psychotropic medications. As such there is a possibility that the drugs affected the DNA methylation differences between the PD and healthy subjects. In addition, some DNA methylation sites have been reported to be influenced by smoking [60]. In this study, we could not adjust for such smoking effects as we did not have data on the smoking status of the healthy control subjects. However, when we examined the distributions of $M$ values of the significant $\mathrm{CpG}$ sites between smokers and non-smokers among the PD subjects, we found that there was no effect of smoking for these sites (Additional file 1: Figure S8).

In conclusion, there might not be any $\mathrm{CpG}$ sites with DNA methylation differences that have a large effect on PD. However, we obtained some intriguing results: the hypomethylated $\mathrm{CpG}$ sites annotated to genes associated with the leukocyte activation pathway and the higher proportion of $\mathrm{CD} 4^{+} \mathrm{T}$ cells in PD. There is a possibility that several $\mathrm{CpG}$ sites with small effects, especially those that are related to immunity, are associated, together as a group, with PD. Further replication studies with larger number of samples are necessary to confirm the findings of this study.

\section{Conclusions}

We performed the EWAS of PD and identified $40 \mathrm{CpG}$ sites of which the levels of DNA methylation were significantly different between PD and healthy control subjects. Some of these CpG sites have the possibility to be related the "positive regulation of lymphocyte activation" pathway. Such CpG sites with small effects might be associated, together as a group, with PD.

\section{Methods}

\section{Subjects}

DNA samples for the EWAS were obtained from our PD and healthy control sample set: patients with PD $(N=48)$ and age- and sex-matched healthy control subjects $(N=$ 48) were recruited from among Japanese individuals living in Tokyo and Nagoya, located in the center of mainland Japan (Additional file 4: Table S8. These samples other than one discordant monozygotic twins were from unrelated PD patients and healthy control subjects. Each PD patient was diagnosed according to the Diagnostic and Statistical Manual of Mental Disorders, 4th Edition (DSM-IV) criteria [61] based on responses to the Mini International Neuropsychiatric Interview (MINI) [62] and clinical records. Healthy control subjects were interviewed by psychiatrists and were asked to fill out a questionnaire, MINI, in order to exclude those with a history of a major psychiatric illness, including PD.

\section{Epigenome-wide DNA methylation analysis}

Genomic DNA (PD, $N=48$; control, $N=48$ ) was extracted from leukocytes in whole blood by the standard phenol chloroform method (Wizard genomic DNA purification kit, Promega Corporation, WI, USA). DNA samples were first bisulfite-converted using a kit for the bisulfite conversion of DNA (EZ DNA Methylation ${ }^{\text {Tx }}$ Kit, Zymo Research, Irvine, CA, USA). For all samples, the DNA methylation levels of cytosine residues across the genome were examined with a DNA methylation array (Infinium ${ }^{\circ}$ Human Methylation 450K BeadChip, Illumina Inc.) according to the manufacturer's protocol. Briefly, the bisulfiteconverted DNA samples underwent whole-genome amplification and were fragmented and hybridized on BeadChip. After hybridization of the fragmented DNA with their complementary probe sequences, the DNA methylation status was determined through a single-base extension step. The arrays were imaged with a high-precision scanner (iScan system, Illumina Inc.), and the signal intensities were extracted using a software package (GenomeStudio Software, Illumina Inc.). The DNA methylation status of each cytosine residue was evaluated with the $\beta$ value, which is the ratio of the signal from the methylated probe divided by the total signal intensity. The $\beta$ value ranges from 0 (unmethylated) to 1 (completely methylated).

\section{Data filtering and normalization}

Data filtering and processing were performed for quality control of the calculated $\beta$ values. $\beta$ values with a detection $P$ value $<0.01$ were treated as missing values. We then calculated the ratio of the detected $\beta$ values to all of the examined $\beta$ values $(N=96)$ for each probe; this was defined as the probe call rate. Probes that met the following conditions were used in the subsequent 
analyses: (1) probe call rate $>95 \%$; (2) probe not on a sex chromosome; (3) probe not including a single-nucleotide polymorphism (SNP) with a minor allele frequency $\geq 0.05$; and (4) probe not reported to be cross-reactive [63] (Additional file 1: Figure S5). As mentioned in the last criterion, we excluded cross-reactive probes that were reported to co-hybridize to alternate sequences that are highly homologous $(<4$ base mismatches among 50 bases) to the intended targets [63]. Furthermore, we created a list of possible cross-reactive probes that have unintended target sequences identical to the 20-base sequence from the $5^{\prime}$ end of each intended target (Additional file 5: Table S9). The 20 bases from the 5' end of each target were mapped against the reference sequence (Genome Reference Consortium Human Reference 37 (GCA_000001405.1)) using BLAST (https://blast.ncbi.nlm.nih.gov/Blast.cgi). In examining significant probes, we excluded the probes that were on the list.

After the filtering, data normalization was performed, with the following pipeline, Lumi: quantile normalization (QN; correction for the distributions of the pooled probes) + beta-mixture quantile (BMIQ) normalization (correction for probe design bias) + correction for the batch effect (ComBat). First, the distributions of the pooled methylated and unmethylated probes were quantile normalized using the Lumi package under the assumption that they were similar between different samples [64]. A beta-mixture QN method was used to correct probe design bias with BMIQ normalization [65]. Finally, an empirical Bayes batch-correction method, ComBat [66], was employed to control for batch effects among arrays. In order to detect PDassociated DMPs, the original $\beta$ values were converted to $M$ values via the logit transformation [67] and used for performing the case control analysis. As for probes on $\mathrm{X}$ chromosome, the data filtering and normalization were performed in the same way separately only with the female samples (PD, $N=31$, control, $N=31$ ) (Additional file 1: Figure S8).

\section{Prediction of the DNA methylation age and the distributions of leukocyte subsets}

DNA methylation age (DNAm age) was defined as the age estimated from the DNA methylation status data of several CpG sites. We predicted the DNAm age to evaluate the reliability of the assay in both $\mathrm{PD}$ and healthy control subjects. DNAm age was estimated using the EWAS data following the algorithm reported in a previous study [24]. As for the analysis of the estimated DNAm age, the data were normalized according to the previous report [24], because the probes used in this analysis were a portion of the total probes and they did not include any type II probe. The estimated DNAm age was compared with chronological age by calculating Pearson's correlation coefficients.

Furthermore, DNA methylation data were used to predict the cell mixture distributions of leukocyte subsets [30] to examine the possibility that cell mixture distributions differ between PD and healthy subjects. The proportions of leukocyte subsets (natural killer cells, B cells, CD $4^{+} \mathrm{T}$ cells, $\mathrm{CD}^{+} \mathrm{T}$ cells, monocytes, and granulocytes) were estimated using a published algorithm [30] with an $\mathrm{R}$ package, Minfi. Briefly, the $\beta$ values of $\mathrm{CpG}$ sites, which correspond to putative differentially methylated sites among leukocyte subsets and that enable them to be distinguished, were selected. The selected $\beta$ values were applied to the analysis, which resembled a regression calibration, as it can be considered a surrogate measure of the distribution of leukocyte cell mixtures [30]. The estimated proportions of leukocyte subsets were compared between the PD and control subjects. Additionally, we estimated abundance measures of plasmablasts, $\mathrm{CD}^{+} \mathrm{CD} 28^{-} \mathrm{CD} 45 \mathrm{RA}^{-} \mathrm{T}$ cells, naive $\mathrm{CD}^{+}{ }^{+} \mathrm{T}$ cells, and naive $\mathrm{CD} 4^{+} \mathrm{T}$ cells using the epigenetic clock software [24].

\section{Pathway analysis}

A pathway analysis was performed using the MetaCore ${ }^{\mathrm{TM}}$ platform (version 6.24 build 67895, Thomson Reuters, New York, NY, USA). Genes annotated to significant CpG sites were examined to determine whether they had any enrichment of gene sets for biological processes and molecular functions in the GO database (http://geneontology.org/) [68]. To be more precise, if the significant $\mathrm{CpG}$ sites were located in regions within 1500 bp from a transcription start site, 5' UTR, body, and 3' UTR of genes, the genes were annotated to the CpG sites and included in the pathway analysis. Since gene sets with large numbers of genes have a tendency to represent broader categories and have no useful biological meaning, gene sets with more than 500 genes were disregarded [69]. Gene sets with less than five registered genes or five consequent genes annotated from a list of examined genes were also disregarded because such gene sets are worthy of little attention in a pathway-based approach. Furthermore, we also used another method of GO-based pathway analysis, GOseq [70], in which bias caused by the different numbers of probes associated with each gene can be corrected [70, 71]. Pathways identified using the MetaCore ${ }^{\mathrm{Tm}}$ platform, but not replicated with GOseq analysis, were excluded from the list of significant pathways.

\section{Statistical analysis}

The Wilcoxon rank sum test was employed to compare the proportions of the leukocyte subsets between the PD 
and control subjects. The Bonferroni correction was applied to adjust for multiple comparisons.

For the EWAS, significant associations were assessed by linear regression analysis with adjustments for the effects of the predicted proportions of leukocyte subsets using $M$ values at a false discovery rate (FDR) of $5 \%$. To check the effect of smoking on the significant sites, adjusted $M$ values were compared between smokers and non-smokers in PD group using $t$ test.

All analyses were performed using $\mathrm{R}$ software.

\section{Additional files}

Additional file 1: Figures S1-S8. Figures which were used for the quality check of the DNA methylation array data, filtering procedure, and additional leukocyte subset analysis and check for smoking effect are indicated. (PDF 727kb)

Additional file 2: Tables S1-S5. Results of probes in the gene regions of which DNA methylation were previously reported to be associated with anxiety disorders. (PDF $146 \mathrm{~kb}$ )

Additional file 3: Table S6 and S7. Blood-brain correlations of the significant $C p G$ sites and meQTL sites found in the significant CpG sites. (PDF $40 \mathrm{~kb}$ )

Additional file 4: Table S8. Demographic characteristics of samples. (PDF $34 \mathrm{~kb}$ )

Additional file 5: Table S9. Probe IDs of possible cross-reactive probes. (XLSX $446 \mathrm{~kb})$

\section{Acknowledgements}

We would like to express our thanks to Associate Professor Dr. Akihiro Fujimoto, Department of Drug Discovery Medicine, Graduate School of Medicine, Kyoto University, for the technical assistance.

\section{Funding}

This study is funded by JSPS (JSPS KAKENHI Grant Numbers 15J04964, 26461712, and 25461723) and the Takeda Science Foundation in Japan.

\section{Availability of data and materials}

The datasets of the current study are freely available from the National Bioscience Database Center (NBDC) website (http://biosciencedbc.jp/en/).

\section{Authors' contributions}

MS-S, TO, TM, KT, and TS designed the study. MS-S, TO, TM, KT, and TS wrote the manuscript. MS-S contributed to the data analyses. TU, YK, MT, KK, HK, $H T$, and YO collected the samples. TO, TU, KT, and TS contributed to the reagents, materials, and analysis tools. $\mathrm{MB}$ and $\mathrm{KI}$ provided technical assistance. All authors read and approved the final manuscript.

\section{Competing interests}

The authors declare that they have no competing interests.

\section{Consent for publication}

Individual person's data are not contained.

\section{Ethics approval and consent to participate}

Written informed consent was obtained from each subject. Ethical approva was obtained from the research ethics committees of relevant institutions (The University of Tokyo and Mie University) (G0639-(32))

\section{Author details}

'Department of Human Genetics, Graduate School of Medicine, The University of Tokyo, 7-3-1 Hongo, Bunkyo Ward, Tokyo 113-0033, Japan. ${ }^{2}$ Graduate School of Clinical Psychology, Teikyo Heisei University Major of Professional Clinical Psychology, 2-51-4 Higashiikebukuro, Toshima Ward, Tokyo 171-0014, Japan. ${ }^{3}$ Department of Psychiatry and Behavioral Sciences,
Tokyo Metropolitan Institute of Medical Science, 2-1-6 Kamikitazawa, Setagaya Ward, Tokyo 156-8506, Japan. ${ }^{4}$ Division for Environment, Health and Safety, The University of Tokyo, 7-3-1 Hongo, Bunkyo Ward, Tokyo 113-0033, Japan. ${ }^{5}$ Department of Psychiatry, Shonan Kamakura General Hospital, 1370-1 Okamoto, Kamakura City, Kanagawa 247-8533, Japan. ${ }^{6}$ Department of Molecular Brain Science, Graduate School of Medical Sciences, Kumamoto University, 1-1-1 Honjo, Chuo Ward, Kumamoto City, Kumamoto 860-8556, Japan. ${ }^{7}$ Department of Neuropsychiatry, Teikyo University School of Medicine, 2-11-1 Kaga, Itabashi Ward, Tokyo 173-0003, Japan. ${ }^{8}$ Department of Neuropsychiatry, Graduate School of Medicine, The University of Tokyo, 7-3-1 Hongo, Bunkyo Ward, Tokyo 113-0033, Japan. ${ }^{9}$ Panic Disorder Research Center, Warakukai Med Corp, 3-9-18 Akasaka, Minato Ward, Tokyo 107-0052, Japan. ${ }^{10}$ Department of Psychiatry, Institute of Medical Life Science, Graduate School of Medicine, Mie University, 2-174 Edobashi, Tsu City, Mie 514-8502, Japan. ${ }^{11}$ Department of Psychiatry, Koseikai Michinoo Hospital, 1-1 Nijigaokamachi, Nagasaki City, Nagasaki 852-8055, Japan. ${ }^{12}$ Department of Physical and Health Education, Graduate School of Education, The University of Tokyo, 7-3-1 Hongo, Bunkyo Ward, Tokyo 113-0033, Japan.

Received: 27 August 2016 Accepted: 26 December 2016 Published online: 21 January 2017

\section{References}

1. Hettema JM, Neale MC, Kendler KS. A review and meta-analysis of the genetic epidemiology of anxiety disorders. Am J Psychiatry. 2001;158(10):1568-78.

2. Crowe RR, Noyes R, Pauls DL, Slymen D. A family study of panic disorder. Arch Gen Psychiatry. 1983;40(10):1065-9.

3. Goldstein RB, Wickramaratne PJ, Horwath E, Weissman MM. Familial aggregation and phenomenology of 'early'-onset (at or before age 20 years) panic disorder. Arch Gen Psychiatry. 1997;54(3):271-8.

4. Erhardt A, Czibere L, Roeske D, Lucae S, Unschuld PG, Ripke S, Specht M, Kohli MA, Kloiber S, Ising M, et al. TMEM132D, a new candidate for anxiety phenotypes: evidence from human and mouse studies. Mol Psychiatry. 2011;16(6):647-63.

5. Erhardt A, Akula N, Schumacher J, Czamara D, Karbalai N, Müller-Myhsok B, Mors O, Borglum A, Kristensen AS, Woldbye DP, et al. Replication and metaanalysis of TMEM132D gene variants in panic disorder. Transl Psychiatry. 2012;2, e156.

6. Otowa T, Yoshida E, Sugaya N, Yasuda S, Nishimura Y, Inoue K, Tochigi M, Umekage T, Miyagawa T, Nishida N, et al. Genome-wide association study of panic disorder in the Japanese population. J Hum Genet. 2009;54(2):122-6.

7. Otowa T, Kawamura Y, Nishida N, Sugaya N, Koike A, Yoshida E, Inoue K, Yasuda S, Nishimura Y, Liu X, et al. Meta-analysis of genome-wide association studies for panic disorder in the Japanese population. Transl Psychiatry. 2012;2, e186.

8. Gregersen NO, Lescai F, Liang J, Li Q, Als T, Buttenschøn HN, Hedemand A, Biskopstø M, Wang J, Wang AG, et al. Whole-exome sequencing implicates $\mathrm{DGKH}$ as a risk gene for panic disorder in the Faroese population. Am J Med Genet B Neuropsychiatr Genet. 2016.

9. Portela A, Esteller M. Epigenetic modifications and human disease. Nat Biotechnol. 2010;28(10):1057-68.

10. Hodes GE. Sex, stress, and epigenetics: regulation of behavior in animal models of mood disorders. Biol Sex Differ. 2013:4(1):1.

11. Lou S, Lee HM, Qin H, Li JW, Gao Z, Liu X, Chan LL, KI Lam V, So WY, Wang Y, et al. Whole-genome bisulfite sequencing of multiple individuals reveals complementary roles of promoter and gene body methylation in transcriptional regulation. Genome Biol. 2014;15(7):408.

12. Murphy TM, O'Donovan A, Mullins N, O'Farrelly C, McCann A, Malone K. Anxiety is associated with higher levels of global DNA methylation and altered expression of epigenetic and interleukin-6 genes. Psychiatr Genet. 2014

13. Gelernter J. Genetics of complex traits in psychiatry. Biol Psychiatry. 2015:77(1):36-42.

14. Shimada-Sugimoto M, Otowa T, Hettema JM. Genetics of anxiety disorders: genetic epidemiological and molecular studies in humans. Psychiatry Clin Neurosci. 2015;69(7):388-401.

15. Ziegler C, Dannlowski U, Bräuer D, Stevens S, Laeger I, Wittmann H, Kugel H, Dobel C, Hurlemann R, Reif A, et al. Oxytocin receptor gene methylation-converging multi-level evidence for a role in social anxiety. Neuropsychopharmacology. 2015. 
16. Domschke K, Tidow N, Schrempf M, Schwarte K, Klauke B, Reif A, Kersting A, Arolt $\mathrm{V}$, Zwanzger $\mathrm{P}$, Deckert J. Epigenetic signature of panic disorder: a role of glutamate decarboxylase 1 (GAD1) DNA hypomethylation? Prog Neuropsychopharmacol Biol Psychiatry. 2013;46:189-96.

17. Ziegler C, Richter J, Mahr M, Gajewska A, Schiele MA, Gehrmann A, Schmidt B, Lesch KP, Lang T, Helbig-Lang S, et al. MAOA gene hypomethylation in panic disorder-reversibility of an epigenetic risk pattern by psychotherapy. Transl Psychiatry. 2016;6, e773.

18. Domschke K, Tidow N, Kuithan H, Schwarte K, Klauke B, Ambrée O, Reif A, Schmidt H, Arolt V, Kersting A, et al. Monoamine oxidase A gene DNA hypomethylation — a risk factor for panic disorder? Int J Neuropsychopharmacol. 2012;15(9):1217-28.

19. Roberts S, Lester KJ, Hudson JL, Rapee RM, Creswell C, Cooper PJ, Thirlwall KJ Coleman JR, Breen G, Wong CC, et al. Serotonin tranporter methylation and response to cognitive behaviour therapy in children with anxiety disorders. Transl Psychiatry. 2014;4, e444.

20. Esler M, Alvarenga M, Pier C, Richards J, El-Osta A, Barton D, Haikerwal D, Kaye D, Schlaich M, Guo L, et al. The neuronal noradrenaline transporter, anxiety and cardiovascular disease. J Psychopharmacol. 2006;20(4 Suppl):60-6.

21. Esler M, Eikelis N, Schlaich M, Lambert G, Alvarenga M, Kaye D, El-Osta A, Guo L, Barton D, Pier C, et al. Human sympathetic nerve biology: parallel influences of stress and epigenetics in essential hypertension and panic disorder. Ann N Y Acad Sci. 2008;1148:338-48.

22. Bayles R, Baker EK, Jowett JB, Barton D, Esler M, El-Osta A, Lambert G. Methylation of the SLC6a2 gene promoter in major depression and panic disorder. PLoS One. 2013;8(12), e83223.

23. Heyn H, Li N, Ferreira HJ, Moran S, Pisano DG, Gomez A, Diez J, SanchezMut JV, Setien F, Carmona FJ, et al. Distinct DNA methylomes of newborns and centenarians. Proc Natl Acad Sci U S A. 2012;109(26):10522-7.

24. Horvath S. DNA methylation age of human tissues and cell types. Genome Biol. 2013;14(10):R115.

25. Houseman EA, Accomando WP, Koestler DC, Christensen BC, Marsit CJ, Nelson HH, Wiencke JK, Kelsey KT. DNA methylation arrays as surrogate measures of cell mixture distribution. BMC Bioinformatics. 2012;13:86.

26. Gao X, Jia M, Zhang Y, Breitling LP, Brenner H. DNA methylation changes of whole blood cells in response to active smoking exposure in adults: a systematic review of DNA methylation studies. Clin Epigenetics. 2015;7:113.

27. Toperoff G, Aran D, Kark JD, Rosenberg M, Dubnikov T, Nissan B, Wainstein J, Friedlander Y, Levy-Lahad E, Glaser B, et al. Genome-wide survey reveals predisposing diabetes type 2-related DNA methylation variations in human peripheral blood. Hum Mol Genet. 2012;21(2):371-83.

28. Kaneda A, Matsusaka K, Sakai E, Funata S. DNA methylation accumulation and its predetermination of future cancer phenotypes. J Biochem. 2014; 156(2):63-72.

29. Slieker RC, Bos SD, Goeman JJ, Bovée JV, Talens RP, van der Breggen R, Suchiman HE, Lameijer EW, Putter $\mathrm{H}$, van den Akker EB, et al. Identification and systematic annotation of tissue-specific differentially methylated regions using the Illumina 450 k array. Epigenetics Chromatin. 2013;6(1):26

30. Jaffe $A E$, Irizarry RA. Accounting for cellular heterogeneity is critical in epigenome-wide association studies. Genome Biol. 2014;15(2):R31.

31. Bibikova M, Barnes B, Tsan C, Ho V, Klotzle B, Le JM, Delano D, Zhang L, Schroth GP, Gunderson KL, et al. High density DNA methylation array with single CpG site resolution. Genomics. 2011;98(4):288-95.

32. Wang T, Guan W, Lin J, Boutaoui N, Canino G, Luo J, Celedón JC, Chen W. A systematic study of normalization methods for Infinium $450 \mathrm{~K}$ methylation data using whole-genome bisulfite sequencing data. Epigenetics. 2015;10(7):662-9.

33. Szyf M. Nongenetic inheritance and transgenerational epigenetics. Trends Mol Med. 2014

34. Feil R, Fraga MF. Epigenetics and the environment: emerging patterns and implications. Nat Rev Genet. 2011;13(2):97-109.

35. Numata S, Ishii K, Tajima A, Iga J, Kinoshita M, Watanabe S, Umehara H, Fuchikami M, Okada S, Boku S, et al. Blood diagnostic biomarkers for major depressive disorder using multiplex DNA methylation profiles: discovery and validation. Epigenetics. 2015;10(2):135-41.

36. Dempster EL, Wong CC, Lester KJ, Burrage J, Gregory AM, Mill J, Eley TC. Genome-wide methylomic analysis of monozygotic twins discordant for adolescent depression. Biol Psychiatry. 2014;76(12):977-83.

37. Wang D, Liu X, Zhou Y, Xie H, Hong X, Tsai HJ, Wang G, Liu R, Wang X. Individual variation and longitudinal pattern of genome-wide DNA methylation from birth to the first two years of life. Epigenetics. 2012;7(6):594-605.
38. Córdova-Palomera A, Fatjó-Vilas M, Gastó C, Navarro V, Krebs MO, Fañanás L. Genome-wide methylation study on depression: differential methylation and variable methylation in monozygotic twins. Transl Psychiatry. 2015;5, e557.

39. Wockner LF, Noble EP, Lawford BR, Young RM, Morris CP, Whitehall VL, Voisey J. Genome-wide DNA methylation analysis of human brain tissue from schizophrenia patients. Transl Psychiatry. 2014;4, e339.

40. Wockner LF, Morris CP, Noble EP, Lawford BR, Whitehall VL, Young RM, Voisey J. Brain-specific epigenetic markers of schizophrenia. Transl Psychiatry. 2015;5, e680

41. Kinoshita M, Numata S, Tajima A, Ohi K, Hashimoto R, Shimodera S, Imoto I, Takeda M, Ohmori T. Aberrant DNA methylation of blood in schizophrenia by adjusting for estimated cellular proportions. Neuromolecular Med. 2014; 16(4):697-703.

42. Dempster EL, Pidsley R, Schalkwyk LC, Owens S, Georgiades A, Kane F, Kalidindi S, Picchioni M, Kravariti E, Toulopoulou T, et al. Disease-associated epigenetic changes in monozygotic twins discordant for schizophrenia and bipolar disorder. Hum Mol Genet. 2011;20(24):4786-96.

43. Ball MP, Li JB, Gao Y, Lee JH, LeProust EM, Park IH, Xie B, Daley GQ, Church GM. Targeted and genome-scale strategies reveal gene-body methylation signatures in human cells. Nat Biotechnol. 2009;27(4):361-8.

44. Rauch TA, Wu X, Zhong X, Riggs AD, Pfeifer GP. A human B cell methylome at 100-base pair resolution. Proc Natl Acad Sci U S A. 2009;106(3):671-8.

45. Shimada-Sugimoto M, Otowa T, Miyagawa T, Khor SS, Kashiwase K, Sugaya N, Kawamura Y, Umekage T, Kojima H, Saji H, et al. Immune-related pathways including HLA-DRB1(*)13:02 are associated with panic disorder. Brain Behav Immun. 2015;46:96-103.

46. Zheng SL, Li ZY, Song J, Liu JM, Miao CY. Metrnl: a secreted protein with new emerging functions. Acta Pharmacol Sin. 2016:37(5):571-9.

47. Howe AS, Buttenschøn HN, Bani-Fatemi A, Maron E, Otowa T, Erhardt A, Binder EB, Gregersen NO, Mors O, Woldbye DP, et al. Candidate genes in panic disorder: meta-analyses of 23 common variants in major anxiogenic pathways. Mol Psychiatry. 2015.

48. Marazziti D, Ambrogi F, Vanacore R, Mignani V, Savino M, Palego L, Cassano GB, Akiskal HS: Immune cell imbalance in major depressive and panic disorders. Neuropsychobiology. 1992;26(1-2):23-26

49. Schleifer SJ, Keller SE, Bartlett JA. Panic disorder and immunity: few effects on circulating lymphocytes, mitogen response, and NK cell activity. Brain Behav Immun. 2002;16(6):698-705.

50. Manfro GG, Pollack MH, Otto MW, Worthington JJ, Rosenbaum JF, Scott EL, Kradin RL. Cell-surface expression of L-selectin (CD62L) by blood lymphocytes: correlates with affective parameters and severity of panic disorder. Depress Anxiety. 2000;11(1):31-7.

51. Park JE, Kim SW, Park Q, Jeong DU, Yu BH. Lymphocyte subsets and mood states in panic disorder patients. J Korean Med Sci. 2005;20(2):215-9.

52. Sapienza C, Lee J, Powell J, Erinle O, Yafai F, Reichert J, Siraj ES, Madaio M. DNA methylation profiling identifies epigenetic differences between diabetes patients with ESRD and diabetes patients without nephropathy. Epigenetics. 2011;6(1):20-8.

53. Kaminsky Z, Tochigi M, Jia P, Pal M, Mill J, Kwan A, loshikhes I, Vincent JB, Kennedy JL, Strauss J, et al. A multi-tissue analysis identifies HLA complex group 9 gene methylation differences in bipolar disorder. Mol Psychiatry. 2012;17(7):728-40

54. Davies MN, Volta M, Pidsley R, Lunnon K, Dixit A, Lovestone S, Coarfa C, Harris RA, Milosavljevic A, Troakes C, et al. Functional annotation of the human brain methylome identifies tissue-specific epigenetic variation across brain and blood. Genome Biol. 2012;13(6):R43.

55. Hannon E, Lunnon K, Schalkwyk L, Mill J. Interindividual methylomic variation across blood, cortex, and cerebellum: implications for epigenetic studies of neurological and neuropsychiatric phenotypes. Epigenetics. 2015;10(11):1024-32.

56. Andlauer TF, Buck D, Antony G, Bayas A, Bechmann L, Berthele A, Chan A, Gasperi C, Gold R, Graetz C, et al. Novel multiple sclerosis susceptibility loci implicated in epigenetic regulation. Sci Adv. 2016;2(6), e1501678.

57. Hannon E, Spiers H, Viana J, Pidsley R, Burrage J, Murphy TM, Troakes C, Turecki G, O'Donovan MC, Schalkwyk LC, et al. Methylation QTLs in the developing brain and their enrichment in schizophrenia risk loci. Nat Neurosci. 2016;19(1):48-54.

58. Lemire $\mathrm{M}$, Zaidi $\mathrm{SH}$, Ban $\mathrm{M}$, et al. Long-range epigenetic regulation is conferred by genetic variation located at thousands of independent loci. Nat Commun. 2015;6:6326.

59. Dong E, Nelson M, Grayson DR, Costa E, Guidotti A. Clozapine and sulpiride but not haloperidol or olanzapine activate brain DNA demethylation. Proc Natl Acad Sci U S A. 2008;105(36):13614-9. 
60. Joehanes R, Just AC, Marioni RE, Pilling LC, Reynolds LM, Mandaviya PR, Guan W, Xu T, Elks CE, Aslibekyan S, et al. Epigenetic signatures of cigarette smoking. Circ Cardiovasc Genet. 2016;9(5):436-47.

61. American Psychiatric Association. Diagnostic and Statistical Manual of Mental Disorders, Fourth Edition (DSM-4). Washington, DC: American psychiatric press; 1994.

62. Sheehan DV, Lecrubier Y, Sheehan KH, Amorim P, Janavs J, Weiller E, Hergueta T, Baker R, Dunbar GC. The Mini-International Neuropsychiatric Interview (M.I.N.I.): the development and validation of a structured diagnostic psychiatric interview for DSM-IV and ICD-10. J Clin Psychiatry. 1998;59 Suppl 20:22-33. quiz 34-57.

63. Chen YA, Lemire M, Choufani S, Butcher DT, Grafodatskaya D, Zanke BW, Gallinger S, Hudson TJ, Weksberg R. Discovery of cross-reactive probes and polymorphic CpGs in the Illumina Infinium HumanMethylation450 microarray. Epigenetics. 2013;8(2):203-9.

64. Du P, Kibbe WA. Lin SM: lumi: a pipeline for processing Illumina microarray. Bioinformatics. 2008;24(13):1547-8.

65. Teschendorff AE, Marabita F, Lechner M, Bartlett T, Tegner J, Gomez-Cabrero D, Beck S. A beta-mixture quantile normalization method for correcting probe design bias in Illumina Infinium 450 k DNA methylation data. Bioinformatics. 2013;29(2):189-96.

66. Johnson WE, Li C, Rabinovic A. Adjusting batch effects in microarray expression data using empirical Bayes methods. Biostatistics. 2007;8(1):118-27.

67. Du P, Zhang X, Huang CC, Jafari N, Kibbe WA, Hou L, Lin SM. Comparison of beta-value and $\mathrm{M}$-value methods for quantifying methylation levels by microarray analysis. BMC Bioinformatics. 2010;11:587.

68. Ashburner M, Ball CA, Blake JA, Botstein D, Butler H, Cherry JM, Davis AP, Dolinski K, Dwight SS, Eppig JT, et al. Gene ontology: tool for the unification of biology. The Gene Ontology Consortium. Nat Genet. 2000;25(1):25-9.

69. Pan W, Kwak IY, Wei P. A powerful pathway-based adaptive test for genetic association with common or rare variants. Am J Hum Genet. 2015;97(1):86-98.

70. Young MD, Wakefield MJ, Smyth GK, Oshlack A. Gene ontology analysis for RNA-seq: accounting for selection bias. Genome Biol. 2010;11(2):R14.

71. Geeleher P, Hartnett L, Egan LJ, Golden A, Raja Ali RA, Seoighe C. Gene-set analysis is severely biased when applied to genome-wide methylation data. Bioinformatics. 2013;29(15):1851-7.

\section{Submit your next manuscript to BioMed Central and we will help you at every step:}

- We accept pre-submission inquiries

- Our selector tool helps you to find the most relevant journal

- We provide round the clock customer support

- Convenient online submission

- Thorough peer review

- Inclusion in PubMed and all major indexing services

- Maximum visibility for your research

Submit your manuscript at www.biomedcentral.com/submit

) Biomed Central 